responsabilizarnos. También debemos responsabilizarnos del pasado en el que no hemos participado, pero que nos condiciona. Responsabilizarse, según su interpretación, quiere decir asumir las consecuencias, evitando que los errores caigan en el olvido.

La segunda parte del libro se centra en el análisis del pensamiento de algunas filósofas del siglo XX, importantes en su momento y casi olvidadas después, ya que la discriminación sobre el trabajo intelectual de las mujeres se nota mucho más en el menosprecio o el olvido de sus aportes que en su menor presencia en el espacio público en cada momento. Así, el problema se bifurca entre el difícil reconocimiento: "Cuando una autora hace una obra diferente se arriesga a no ser vista y cuando su obra es asimilable a la corriente general, su aportación será considerada superflua" (94) y la aún más difícil inclusión de los aportes femeninos en la gran tradición filosófica. Esto no es sólo una consecuencia de la importancia mayor o menor de los aportes, sino de opciones políticas que determinan qué es lo que se recuerda y qué es lo que se olvida y la memoria académica funciona al respecto como las normas de transmisión de los apellidos, que borran en cada generación el reconocimiento de las madres.

Hábilmente, Birulés saca de esta situación algunos aspectos positivos, ya que las filósofas del siglo XX como Simone Weil, Hannah Arendt, María Zambrano, Suzanne Langero, o Sarah Kofman "se expresan con libertad [...] parecen saber que la universalidad del pensamiento no tiene que ver con su neutralidad y que el canon no las incluirá [...] por tanto hablan sin temor a equivocarse [...] desde su condición de parias, no se han sentido intelectualmente ni moralmente vinculadas a la tradición [...] pero parecen haber estado pendientes de lo que hacían las otras". (103-105)

En resumen, se trata de un libro denso lleno de ideas y sugerencias, que se lee con interés y que aporta en cada página reflexiones enriquecedoras e innovadoras. El hecho de que sea una cuidada publicación en catalán implica además un valor añadido.

D.O.I.:

DOLORES JULIANO

Universitat de Barcelona

\title{
Sex, Identity and Hermaphrodites in Iberia, 1500-1800
}

Richard Cleminson y Francisco Vázquez García

Londres, Pickering \& Chatto, 2013

La colección "The Body, Gender and Culture", de Pickering \& Chatto, ha abierto las puertas a los estudios hispánicos de la mano de este volumen, denso y 
fascinante. Es una grata sorpresa, teniendo en cuenta que no resulta frecuente la publicación de una monografía sobre las multiplicidades discursivas en torno al cuerpo y a la sexualidad en los reinos ibéricos de los siglos XVI y XVII desde un enfoque doblemente comparativo (entre, principalmente, Castilla y Portugal y entre ambos y el resto de Europa). Richard Cleminson y Francisco Vázquez García resultan sobradamente conocidos, tanto por sus aportaciones individuales como por dos libros indispensables redactados a cuatro manos: 'Los invisibles': A History of Male Homosexuality in Spain, 1850-1940 y Hermaphroditism, Medical Science and Sexual Identity in Spain, 1850-1960 (ambos publicados por University of Wales Press, en 2007 y 2009, y ya traducidos al español). De hecho, Sex, Identity and Hermaphrodites in Iberia, 1500-1800 nace al calor de la monografía de 2009 y demuestra el indudable interés de esta línea de investigación interdisciplinaria, en donde deben convivir la consulta de las fuentes primarias, el diálogo con la variada bibliografía secundaria y el análisis en discusión permanente con investigadores de la talla de Michel Foucault, Thomas Laqueur o Judith Butler. No debe extrañar, por consiguiente, que la solidez de sus aportaciones también se proyecte sobre la estructura misma del libro, de manera que casi la mitad de su extensión se destina a notas, referencias bibliográficas e índices (en cuanto a las primeras, las hay de tal enjundia que uno preferiría que apareciesen en el texto; en lo que atañe a las segundas, hubiese agradecido la separación entre los textos antiguos y las aproximaciones contemporáneas).

En la introducción (1-10), los autores ofrecen una presentación de los contenidos pero, sobre todo, una reflexión acerada sobre los logros de la investigación en torno al hermafroditismo consagrada al período anterior a la Ilustración: el triángulo que delimitan las nociones "sex", "gender" e "historicity" constituyen un punto de partida y un norte que guía este volumen: "the sexed body must be understood in the context of a strict historical analysis" (4). De ahí que ya en este proemio podamos constatar cuanto puede entenderse como una conclusión avanzada, cuando se afirma que, más allá de la convivencia de dos modelos médicos opuestos (el aristotélico y el hipocrático-galénico) en torno al régimen sexo/género, aquello que resulta más relevante serían las controversias y ambigüedades en el ámbito jurídico, científico y teológico. Así, podría apuntarse una nueva vía de interpretación de la comedia barroca o de las "relaciones de sucesos", plagadas de mujeres travestidas y varones disfrazados, a través de una nueva conceptualización de la figura del hermafrodita.

En el primer capítulo, titulado "Marvels, monsters and prodiges: hermaphrodites as natural phenomena in Spain, 1500-1700" (11-39), Cleminson y Vázquez García abordan las fluctuaciones en las aproximaciones al hermafroditismo sobre todo a partir de los tratados científicos y teológicos (Antonio de Torquemada, Martín del Río,...) con el propósito de mostrar como en numerosas piezas del siglo XVI las diferencias entre sexo y género solo se 
iluminaban a través de las ropas o de las ocupaciones, de modo que dominaba el modelo hipocrático unisexual. Esta mirada empezaría a cambiar en la centuria posterior y se proyectaría hacia los estudios anatómicos, pero también hacia la abundante literatura teratológica de la época o en piezas religiosas, como las consagradas a la barbuda (y milagrosa) Santa Paula de Ávila.

Si en este capítulo inicial los autores profundizaban en las ambigüedades de los discursos sobre el género, en el segundo ("Sexual transgression and hermaphroditism: the 'New World' and imperial subjectivity", 41-64), profundizan en diversos testimonios conservados que confirman el trasiego de experiencias y desidentificaciones entre los reinos peninsulares y sus posesiones de ultramar. Algunos de ellos son bien conocidos, como la "autobiografía" de Catalina de Erauso, la celebrada "monja alférez", o Elena de Céspedes; otros, en cambio, habían merecido escasa revisión hasta la fecha, como los casos de Estefanía de Valdaracete y Juan Díaz Donoso. Las interrelaciones entre estas documentaciones permiten análisis muy ricos que profundizan en el sendero recorrido en las páginas precedentes y que demuestran los tímidos cambios de paradigma que se produjeron a partir del siglo XVIII. En efecto, en "The expulsion of the marvellous: the decline of the 'one-sex' model, 1750-1830" (65-84), mediante una atenta aproximación al caso de la monja Fernanda Fernández, por ejemplo, comprobamos que las tesis de Laqueur resultan poco útiles para el contexto hispánico, a diferencia de cuanto acontece en otros países europeos, pues "news about sex changes and hermaphrodites continued to be common currency in intelectual and popular spheres" (65), al tiempo que se abordan los cambios introducidos en la medicina legal. El cuarto capítulo, dedicado a Portugal (85-110), ofrece un repertorio de noticias y documentaciones que confirmaría el flujo científico en torno a la identidad sexual en tierras ibéricas durante los siglos XVI y XVII, el peso intelectual de conversos y marranos en tierras lusitanas o el eco obtenido por personas como Antónia Rodrigues. Al tiempo, sirven para reflexionar sobre la naturaleza y la naturalidad de masculinidades y feminidades - y no solo de hermafroditas - en aquella época.

Debe subrayarse que esta monografía no merece encerrarse en una vitrina de rarezas antiguas. Sería un error imperdonable. El mero recorrido por los archivos y bibliotecas, antiguos y modernos, ya constituye una aportación valiosísima para quienes estén interesadas en las representaciones de las sexualidades hispánicas anteriores al siglo XIX. Pero, además, es una investigación seria y solvente, crítica y original, que analiza los discursos antiguos en torno a la identidad de género e incide implícitamente en debates de nuestra época.

D.O.I.:

RAFAEL M. MÉRIDA JIMÉNEZ

Universitat de Lleida

Centre Dona i Literatura 